\title{
AOR
}

Selected Papers of \#AoIR2021:

The 22nd Annual Conference of the

Association of Internet Researchers

Virtual Event / 13-16 Oct 2021

\section{TECHNOLOGICAL SOVEREIGNTY AND SOCIAL JUSTICE: EXPLORING THE INTERSECTION OF FREE SOFTWARE AND INDIGENOUS KNOWLEDGE}

\author{
Stéphane Couture \\ Université de Montréal \\ Sophie Toupin \\ Concordia University \\ Alejandro Mayoral-Baños \\ York University
}

Questions of independence and sovereignty have long been present with regards to the Internet, cyberspace, and, more broadly, the digital. In 1996, for instance, John Perry Barlow published his now well-known "Declaration of the Independence of Cyberspace" (Barlow, 1996) which claimed that cyberspace was the "new frontier", a kind of "far west" over which nation-states should not have power. This ignited a debate on the relevance of governments to regulate cyberspace (Lessig, 1999). While less present in academic discourses, some have also noted how this way of seeing cyberspace as the new "electronic frontier" is reiterating a settler-colonial metaphor much present in the American imaginary (Eubanks, 1999).

Twenty-five years after Barlow's declaration of independence, notions like "digital sovereignty", "data sovereignty" and "technological sovereignty" are increasingly used in public debates. But while the declaration of the independence of cyberspace opposed state intervention, today's discourses on "sovereignty" are articulated in a symmetrical way, towards the understanding (in academic studies) and calling for (in advocacy work) the power of nation-states to govern their data and their part of the Internet, especially in powerful European or/and BRICS countries (Brazil, Russia, India, China, South Africa - Budnitsky \& Jia, 2018; Polatin-Reuben \& Wright, 2014). However, as we have noted previously (Couture \& Toupin, 2019), many other meanings have been given to the notion of sovereignty. Based on our previous work, we would like to deepen in this presentation two ways in which digital and technological sovereignty departs from a state-oriented perspective.

Suggested Citation (APA): Couture, S., Toupin. S., \& Mayoral-Baños, A. (2021, October). Technological sovereignty and social justice: exploring the intersection of free software and Indigenous knowledge. Paper presented at AolR 2021: The 22nd Annual Conference of the Association of Internet Researchers. Virtual Event: AolR. Retrieved from http://spir.aoir.org. 
First, Indigenous scholars and advocates are calling for data sovereignty in continuity with the larger struggle of Indigenous peoples to reclaim sovereignty over their land, body, and culture. Kukutai and Taylor (2016) argue for instance that data (and digital) sovereignty "has been dominated by national governments and multinational corporations" (Kukutai and Taylor, 2016: 2), and that the voices and rights of Indigenous peoples in relation to the "collection, ownership and application of data about their people, lifeways and territories" (Kukutai and Taylor, 2016: 2) are missing. Not only do these claims go beyond the strict reference to the sovereignty of established nationstates, but they also transcend the idea of mere control of data and technologies to emphasize the need for Indigenous frameworks to collect and/or create this data.

Second, social justice activists also put forward the concept of "technological sovereignty" in a way that significantly differs from more dominant policy-oriented and state-centric perspectives, and aligns more with practices of developing digital technologies and infrastructures, using free software, servers, and encryption-based technologies, which have been designed by them and for them (Nitot, 2016; Haché, 2017). This perspective is quite distinct from the idea of digital sovereignty as promoted by nation-states, as it often emphasizes alternative and community-based technological making.

These two perspectives seem to share what can be called an anti-hegemonic perspective on technological sovereignty. While they may reinforce each other, they may also differ on certain perspectives. It is noted for instance that the philosophy of information sharing in free and open-source software might foster the usage and misappropriation of knowledge held by Indigenous communities (Christen, 2012; Gida, 2019; Mayoral-Baños, 2021). Even from the perspective of social justice movements, the sexism prevalent in free software communities (Reagle, 2012) may also be a challenge to the true collective autonomy implied by the metaphor of sovereignty.

This presentation will explore the notion of "technological sovereignty" through Indigenous perspectives as well as those of social movements inspired by free software activism. Conceptually, our analysis is based on a constructionist approach that posits that metaphors organize users' perceptions and contribute to creating new realities (Krippendorf 1993; Proulx 2007). What is the role of the metaphor of "sovereignty" in reconfiguring Indigenous and social justice activism, in relation to the Internet? What are the commonalities between these perspectives? How are they reinforcing or contradicting each other?

This analysis will be foremost based on, and prolong a previous study by the authors which identified different discursive trends around sovereignty (anonymous reference). Methodologically, our approach is grounded in discourse analysis and reviews of academic and activist literature that has mobilized metaphors of digital sovereignty. We will look at a sample of texts, and try to bring out some of the challenges of articulating them. In doing so, we intend to contribute to the theme of this year's AOIR conference Independence - by looking at the critical discourses of Indigenous people and social activists through the lens of the metaphor of digital (technological/data) sovereignty. 


\section{References}

Barlow, J. P. (1996, February 8). A Declaration of the Independence of Cyberspace. Electronic Frontier Foundation. https://www.eff.org/fr/cyberspace-independence

Budnitsky, S., \& Jia, L. (2018). Branding Internet sovereignty: Digital media and the Chinese-Russian cyberalliance. European Journal of Cultural Studies, 21(5), 594-613. https://doi.org/10.1177/1367549417751151

Christen, K. (2012). Does Information Really Want to be Free? Indigenous Knowledge Systems and the Question of Openness. International Journal of Communication, 6, 24.

Couture, S., \& Toupin, S. (2019). What does the notion of "sovereignty" mean when referring to the digital? New Media \& Society, 21(10), 2305-2322. https://doi.org/10.1177/1461444819865984

Eubanks, V. (1999, December 19). The Mythography of the "New" Frontier. Media in Transition Conference. http://web.mit.edu/m-i-t/articles/index_eubanks.html

Gida. (2019). CARE Principles for Indigenous Data Governance. The Global Indigenous Data Alliance.

https://static1.squarespace.com/static/5d3799de845604000199cd24/t/5da9f4479 ecab221ce848fb2/1571419335217/CARE+Principles_One+Pagers+FINAL_Oct $17 \_2019 . p d f$

Haché, A. (2017). Technological Sovereignty. Mouvements, 79(3), 38-48. http://www.cairn-int.info/revue-mouvements-2014-3-p-38.htm

Krippendorff, K. (1993). Major Metaphors of Communication and some Constructivist Reflections on their Use. Cybernetics \& Human Knowing, 2(1): 325. http://www.asc.upenn.edu/usr/krippendorff/METAPHOR.htm.

Kukutai, T., \& Taylor, J. (2016). Indigenous Data Sovereignty: Toward an Agenda (Vol. 38). Acton ACT, Australia: ANU Press.Lessig, L. (1999). Code: And Other Laws Of Cyberspace (1st U.S. Edition, 3rd Printing edition). Basic Books.

Mayoral-Baños, A. (2021). Tech Anishinaabe Medicine Wheel: Decolonial Design Principles within Digital Technologies through the Development of the Indigenous Friends Platform. Unpublished doctoral dissertation. Graduate Program in Communication and Culture. York University

Nitot, T. (2016). Numérique: Reprendre le contrôle. Framasoft. https://framabook.org/docs/NRC/Numerique_ReprendreLeControle_CCBy_impress.pdf 
Polatin-Reuben, D., \& Wright, J. (2014, July 7). An Internet with BRICS Characteristics: Data Sovereignty and the Balkanisation of the Internet. Workshop on Free and Open Communications on the Internet, FOCI 14. https://www.usenix.org/system/files/conference/foci14/foci14-polatin-reuben.pdf

Proulx, S. (2007). Interroger la métaphore d'une société de l'information: Horizon et limites d'une utopie. Communication et langages, 152:107-124.

Reagle, J. (2012). "Free as in sexist?" Free culture and the gender gap. First Monday, 18(1). http://firstmonday.org/ojs/index.php/fm/article/view/4291 